\title{
Cost-effective support for university students learning via the Web?
}

\author{
David Hawkridge \\ Institute of Educational Technology, The Open University, Milton Keynes
}

Academics and other knowledge-owners are creating millions of Webpages that students can use. Universities are teaching more students off-campus because the costs of on-campus provision cannot be met. Offering courses via the Web seems an attractive alternative. Academics (and students) want the courses to be high quality. Yet quality is often lacking. A course outline gets approval, then aims, objectives and content change rapidly during the teaching. Students' and tutors' inputs' are seldom monitored. Students join conferences only to discover that few classmates participate actively and the tutors' advice is hard to get. Web courses risk acquiring a poor reputation.

To improve quality, academics create teaching Webpages, from which they refer students to printed texts and other Webpages. This is not like writing lecture notes or a journal paper. Pages for students are more like a private conversation: they have to evoke intellectual responses during months of study.

To improve quality, academics set up computer conferences, offering :guidance and bringing students together to exchange views and information. Academics find the tutoring experience overwhelming. The quality and quantity of input start high, but decline rapidly. Rewarding students for participation helps, though judging their input is difficult. Supporting students' critical thinking through conferences is a challenge to any academic.

To improve quality; academics expect students to. submit assignments electronically, with the advantages of fast turnaround and tutorial comment inserted into each assignment. This work resembles on-campus grading/commenting, but as Web-based systems develop with audio and video, designing and assessing new assigniment types is difficult.

Supporting Web-based student learning requires a substantial input of expensive academic time. Is this type of learning more expensive per student than on-campus learning? Can ways be found to make students more independent of their tutors? With quality and costs in mind, can academics provide cost-effective support for students learning via the Web? In this paper Open University examples are used to provide some suggestions. 


\section{The proliferation of Web-based courses}

Academics and other owners of knowledge are making millions of Webpages that students can use. One Web source alone, Lexis-Nexis Universe (http://web.lexis-nexis.com/universe) claims to offer already more than a billion pages to its registered users, many of them students. Another, Eureka (http://eureka.rlg.org), is a catalogue of everything from books and serials to manuscripts, amps, music scores, sound archives, films and photographs, with over 30 million titles.

Universities and colleges are teaching more students off-campus because the costs of expanding on-campus provision cannot be met. The Vice-Chancellor of the Open University (OỤ) said recently (http://www.open.ac.uk/OU/News.html):

: The Government is committed to providing an extra half million places in further and higher education by 2002 . Such expansion is a challenge. But it is a challenge faced by many other countries of the world in even starker terms. Today many countries have populations whose median age is below 25 . In some it is below twenty. In the coming years a tidal wave of young people will engulf existing universities. ' $A$ ' large new university needs to open every week, somewhere in the world, just to keep the participation rate in post-compulsory education constant. In most countries, as in Britain, governments want to improve the participation rate, so even one new campus a week will not do the trick.

Offering courses via the Web, in some sort of virtual university, appears to be an attractive and potentially cost-effective alternative (Verdejo and Davies, 1998 , cover various models). The costs of developing and distributing such courses appear low, particularly when compared with the costs of building new campuses, or even with the costs of developing distance-taught courses of the type used successfully by the OU.

Individual academics are leading the way, but for their own reasons. For example, Greek, at Florida State University (FSU), teaches a 'paperless' undergraduate course about criminology. (http://www.fsi.edu/ crimdo/greek.html). 'Its features include email connections, chat sessions, Web searches and conferences. Also at FSU, Krantz teaches a Web-based course on child development (http://cpd-online.fsu.edu/cpd3220/), described in the next section.

The OU offers a:range of high-quality Web-based courses to students within the European Union (http://www.open.ac.uk). The Master's in Open and . Distance Education (http://www-iet.open.ac.uk/IET/ODLBrochure/VCampus.html) is available worldwide, except in Australia. Unlike the FSU examples, the MA courses include print, video and audio materials, but all have a strong online component.

Academics (and their students) want the courses to be of high quality. Yet quality is often lacking. The worst cases are in some of the so-called 'virtual universities' that spring up so 'virtual' that they have nothing but a mailbox intended to take gullible students' money - and vanish overnight.

Eveni in the better virtual universities a course outline gets approval, but aims, objectives and content may change rapidly during the teaching as new Web sources appear. Many older distance education courses have been through quality assurance procedures during the 
long gestation of their design and manufacture. Editors, course teams and external academic assessors have all played important parts. But similar procedures are difficult to apply during the just-in-time processes that create new Webpages. A new textbook is edited many months before it is sent to students; a new Webpage can be created mere hours, even minutes, before they read it. New procedures for quality assurance are still being developed. Ownership of the intellectual property in Web-based courses is a highly contentious issue (Guernsey and Young, 1998), yet ownership is one of the chief factors that influences quality. Why bother about maintaining high standards if the course doesn't 'belong' to you in some positive sense as a teacher?

Students' and tutors' inputs to Web-based conferences are seldom monitored, although they are encouraged (see Meek et al., 1998, for an example in earth science). In this respect the conferences are like many seminars on campus: usually only those present know what happens. Evaluation is perhaps limited to general feedback at the end of term or semester. Meantime, students on Web-based courses join conferences, expecting to get help, only to discover that few classmates participate actively and tutors' personal advice is hard to get. My own research (Hawkridge et al., 1997) confirms findings quoted elsewhere (e.g. Walker, 1998): about one-third of the class contributes frequently, one-third reads but contributes rather seldom and one-third reads or contributes scarcely at all. Tutors may be friendly and wise but they fall into the same three groupings unless they are monitored or even dragooned.

The Canadian TeleCampus Online Course Database lists over 7,000 courses available online anywhere in the world (http://database.telecampus.com). Many, however, are really no more than correspondence courses with email links between students and their tutors. Very few take more than 150 hours to study. Transferable academic credit from such cases is more or less impossible.

Web-based courses risk acquiring a poor reputation. Worse, it seems as though they may not even be cost-effective, even for distance learning. On-campus, they are almost always an add-on to a campus course, at an add-on cost (see Collis, in press, for European examples). For off-campus use or distance learning, they appear to have low development costs compared with the older materials-based ones, but they incur higher presentation costs per student because the tutors are much more involved, with a large demand for tutoring online. It seems doubtful whether a single Web-based course can serve large numbers of students: such courses may not be able to provide economies of scale like the older print-based courses do.

\section{Improving the quality of Web-based courses}

To improve quality, academics often create teaching pages to which they refer students to printed texts, videos, CD-ROMs and other Web pages. This is not like writing lecture notes or a journal paper (see Yaverbaum and Liebowitz, 1998, for an example from management education; Reed and Afjeh, 1998, for an engineering example). Ideally, pages for students are more like a private conversation: they should evoke intellectual responses during months of study. A good US example is a course on child development (http://cpdonline.fsu.edu/ chd3220/), accessible only to registered students at Florida State University. Krantz took his textbook, digitized during word-processing, and created with it a 
'cybertext' by building in more than 300 clickable links. Many are to Web resources belonging to specialist child agencies. Others are to pages containing definitions, clarifications and amplifications of particular terms and concepts, as well as assignment details. He added colour graphics and photographs, even some short movie clips. Alongside the cybertext is a forum for discussion of course topics. However, he teaches only a handful of students online each year, the rest being face-to-face on campus. The latter can also access the online version.

To improve quality, academics set up computer conferences for students. They offer guidance and bring students together to exchange views and information. Essentially, the online interactions need to be structured well. Academics can find this tutoring experience overwhelming. The quality and number of inputs often start high, but can dwindle rapidly, sometimes alarmingly so. Awarding students for participation helps, though judging their input is difficult. Supporting students' critical thinking through conferences is a challenge to any academic.

To improve quality, academics expect students to submit assignments via the Web. For students, there are the advantages of fast turnaround and detailed tutorial comment inserted into each assignment. For academics, this work closely resembles on-campus grading and commenting, but as improved Web-based systems develop, with audio and video, designing and assessing new types of assignment is becoming difficult.

\section{Supporting student learning via the Web}

Supporting student learning via the Web requires at present substantial inputs of expensive academic time. Even when the Web is used only to provide tutorial support via email, a bulletin board system and conferencing, exceptionally high input is often needed to structure online work by students. Although the level of input can sometimes be attributed more to a tutor's great enthusiasm than to students' needs, low levels of input seem to be associated with much less student activity. Tutors come back to the conferences after a few days away and find 20-30 messages to read: they have to decide which ones they should respond to.

Creating a social environment on the Web, especially at the start of a course; is an important task for the tutors as they try to support student learning. A café (complete with newspapers!), chat and gossip areas, digitized photos and student-only conferences all make sense, but must be provided for. Tutors need to help, so far as they can, those students who feel awkward in this unfamiliar setting. Personal emails are more likely to be appropriate for this purpose than public pages on a bulletin board or conference, yet up to 40 per cent of conference messages may be social in nature (Wilson and Whitelock, 1998b).

Is it likely that this online type of learning may be even more expensive per student than on-campus learning? There is evidence that it may be: in the OU's online courses students' expectations are raised and they ask for substantial support, which they get (Hawkridge et al., 1997; Wilson and Whitelock, 1998b). If professors and other senior staff act as tutors, it certainly is more expensive, since few economies of scale are possible. Reducing the cost may be a matter of division of labour. Professors and others may create the courses, but 'adjunct staff', as the Americans say, should do the tutoring, as part-timers probably, on piecework. 
Can ways be found to make the students more independent of their tutors? If academics set out to structure the students' use of the Web, this may require more investment before the course starts, but cost less in tutors' time once it is being taught. Rada (1998) reports experience at Washington State.

From recent OU experience (see Hawkridge et al., 1997; Mason and Bacsich, 1998; Walker, 1998; Wilson and Whitelock, 1998a and 1998b), five strategies seem useful:

- Schedule the work, thus making clear to students exactly what is expected of them and when. While this introduces some rigidity into the system, it does increase the chances of students working together on the same content. They should be able then to help one another.

- Establish small groups to carry out defined tasks on their own. Within each group, students can choose or be assigned roles: moderator, researcher, reporter; summarizer and so on. Tutors can be reached during the work, but do not actively guide it. The group discusses outcomes and possibly asks the opinion of another group, as well as the tutor. :.

- Organize 'Ask an Expert' or 'Master Class' conference sessions to take the strain off the tutor. An expert is invited (and should normally be paid) to 'meet the students' for up to a week during the course. They question the expert and discuss his or her answers.

- Expect the students to draw on their own experience, where relevant, as much as possible. Tutors still have to guide the discussion, however, as they evaluate the experience and its relevance to the work in hand.

- After the first presentation of the course, ensure that subsequent presentations draw as appropriate on the best work done by previous students on the Web. In other words, make the course experience accumulate.

Wilson and Whitelock (1998b) also suggest that the answers to frequently-asked questions should be posted on the Web, and that in the second year of presentation tutors are likely to spend rather less time online, perhaps as a result of their experience of overload in the first year!

With quality and costs in mind, can we academics provide cost-effective support for university students learning via the Web? Can we move beyond the present 'cottage industry' stage, in which individual academics create and tutor their own Web courses? The answer must be yes, because most of the indicators point to massive Web-based learning before long.

\section{Conclusion}

Rumble (1997) outlines the problems inherent in assessing the cost-effectiveness of supporting students learning at a distance via the Web. Collis (in press), in writing about the cost-effectiveness of telematics applications in campus universities, points out that costs are hard to determine in networks. It does seem unlikely that universities will be able to compare, except at some global level, the costs and effectiveness of using the new technologies to support student learning. Should anyone be concerned? Not if the average cost per student continues to be acceptable politically and to those who pay, including the 
students themselves, I would say. The technologies have entered university teaching and learning. They will not leave. They must be exploited for the benefit of all in universities.

\section{References}

Collis, B. (in press), 'Telematics-supported education for traditional universities in Europe', Performance Improvement Quarterly.

Hawkridge, D., Morgan, A. and Jelfs, A. (1997), 'H801 students' and tutors' use of the electronic workbook and electronic mail', Milton Keynes: Institute of Educational Technology, The Open University.

Mason, R. and Bacsich, P. (1998), 'Embedding computer conferencing into university teaching', Computers and Education, 30 (3/4), 249-58.

Meek, J., Garnett, M. and Grattan, J. (1998), 'Evaluating the impact of Internet provision on students' information-gathering strategies', $A L T-J, 6(1), 57-63$.

Rada, R. (1998), 'Efficiency and effectiveness in computer-supported peer-peer learning', Computers and Education, 30 (3/4), 137-46.

Reed, J.A. and Afjeh, A.A. (1998), 'Developing interactive educational engineering software for the World Wide Web with Java', Computers and Education, 30. (3/4), 183-94.

Rumble, G. (1997), The Costs and Economics of Open and Distance Learning, London: Kogan Page.

Verdejo, F. and Davies, G. (1998), 'The virtual campus: Trends for higher education and training'. Papers from IFIP TC3/WG3.3 \& WG3.6 Joint -Working Conference, 27-29 November 1997, Madrid.

Walker, M. (1998), Using CMC: Guidelines for Course Teams, Milton Keynes: Programme on Learner Use of Media, Institute of Educational Technology, The Open University.

Wilson, T. and Whitelock, D. (1998a ), 'What are the perceived benefits of participating in a computer-mediated communication (CMC) environment for distance learning computer science students?', Computers and Education, 30 (3/4), 259-69.

Wilson, T. and Whitelock, D. (1998b), 'Is it sustainable? A comparison of student and tutor online time across three distance-learning courses', ALT-J, 6(1), 25-31.

Yaverbaum, G.J. and Liebowitz, J. (1998) 'GoFigure Inc: a hypermedia Web-based case', Computers and Education, 30 (3/4), 147-56. 